DOI: $10.13037 /$ ci.vol20n44.6154

\title{
A disputa de narrativas sobre a constituição de um grupo de mulheres no Facebook na campanha presidencial de 2018
}

\section{THE DISPUTE OF NARRATIVES ON THE CONSTITUTION OF A GROUP OF WOMEN IN FACEBOOK IN THE 2018 PRESIDENTIAL CAMPAIGN}

\section{Maria Clara Aquino Bittencourt ${ }^{1}$}

ORCID: http://orcid.org/0000-0001-8230-5921

(Universidade do Vale do Rio dos Sinos, Programa de Pós-Graduação em Ciências da Comunicação. São Leopoldo - RS, Brasil)

\section{Marlon Santa Maria Dias²}

ORCID: http://orcid.org/0000-0002-0175-9217

(Universidade do Vale do Rio dos Sinos, Programa de Pós-Graduação em Ciências da Comunicação. São Leopoldo - RS, Brasil)

Ana Karlice Nascimento de Ávila

ORCID: http://orcid.org/0000-0002-6469-8474

(Universidade do Vale do Rio dos Sinos, Programa de Pós-Graduação em Ciências da Comunicação. São Leopoldo - RS, Brasil) 
Resumo

Propomos pensar a constituição do grupo no Facebook Mulheres Unidas Contra Bolsonaro como um ciberacontecimento. Procuramos articular a narrativa a partir dos sentidos que emergem nas redes digitais e daquilo que a imprensa produz de sentidos em torno do acontecimento, amparados em perspectivas teóricas feministas. $\mathrm{O}$ modo como o grupo surge e repercute, tornando-se notícia e potencializando diferentes narrativas no universo on-line. Percebe-se uma articulação em rede que pauta o jornalismo, mas que pelas forças de um embate polarizado, muitas vezes invisibiliza questões de importância política e social.

Palavras-chave: Ciberacontecimento. Narrativas. Mulheres.

\section{Abstract}

We propose to think about the constitution of the group in Facebook Mulheres Unidas Contra Bolsonaro as a cyberevent. We try to articulate the narrative from the senses that emerge in the digital networks and from what the press produces of meanings around the event, supported by feminist theoretical perspectives. The way the group emerges and reverberates, becoming news and potentiating different narratives in the online universe. We can see a network articulation that guides journalism, but that by the forces of a polarized conflict, often makes invisible issues of political and social importance.

Keywords: Cyberevent. Narratives. Women.

\section{Introdução}

Durante a campanha de $1^{\circ}$ turno das eleições presidenciais de 2018 no Brasil, o candidato Jair Messias Bolsonaro (PSL) já despontava como favorito. Pesquisas realizadas por diferentes institutos mostravam sua ascensão em todos os cenários, desde que o nome do ex-presidente Luiz Inácio Lula da Silva foi retirado da disputa. Ao mesmo tempo, as pesquisas sinalizavam a alta rejeição que o candidato tinha, especialmente entre eleitoras mulheres. Ao final do $1^{\circ}$ turno, Bolsonaro conquistou 46,03\% dos votos, ficando 16 pontos acima do candidato Fernando Haddad (PT), com quem disputou o $2^{\circ}$ turno do pleito. No dia 28 de outubro de 2018, foi eleito presidente com 57,8 milhões de votos.

Dentre os treze candidatos que concorreram ao cargo, Bolsonaro foi o que mais mobilizou discussões em torno de sua candidatura. Capitão reformado do Exército Brasileiro, Bolsonaro foi deputado federal por sete mandatos, com 162 projetos de sua autoria - dos quais apenas dois viraram lei. Em quase 30 anos de Câmara, sua biografia é marcada pela adoção de um discurso violento, com declarações machistas, misóginas, racistas e homofóbicas. Se essas características o fizeram ganhar popularidade, o candidato buscou desvincular-se dessa imagem durante a campanha, para expandir o eleitorado. Ainda assim, foi eleito com um discurso conservador, que vez por outra destaca os feitos 
dos militares durante o período do regime ditatorial ${ }^{1}$ (1964-1985), tendo como figura de apreciação o coronel do Exército Brasileiro Carlos Alberto Brilhante Ustra, ex-chefe do DOI-CODI, um dos órgãos que atou na repressão política ${ }^{2}$.

Maioria do eleitorado - 52,3\%, de acordo com dados do Tribunal Superior Eleitoral - e as que mais comparecem às urnas, as mulheres vivem, historicamente, um processo de apagamento no contexto eleitoral brasileiro (BIROLI, 2018). O país ocupa, por exemplo, a $152^{\mathrm{a}}$ posição no ranking de representatividade feminina na política elaborado pela União Interparlamentar Internacional (UIP), com base em dados de janeiro de 2018. Quando Michel Temer (MDB) assumiu a presidência após o impeachment de Dilma Rousseff, primeira mulher eleita presidenta do país, ganhou as capas dos sites de notícias a foto em que ele posa ao lado de seus 24 ministros, todos homens ${ }^{3}$. O cenário conturbado do pleito de 2018, no entanto, parecia apontar para um novo papel da mulher no cenário político.

Com o crescimento da candidatura de Bolsonaro, mulheres passaram a se articular online em uma tentativa de conter seu avanço na campanha para a Presidência da República. No dia 30 de agosto foi criado no Facebook o grupo Mulheres Unidas Contra Bolsonaro. Em vídeo divulgado no site de rede social ${ }^{4}$, uma das criadoras do grupo contou que a ideia se originou de uma conversa com uma amiga, com a finalidade de alertar a população sobre os posicionamentos do "inominável" - termo como elas se referem a Bolsonaro. Nas primeiras 48 horas, já havia seis mil integrantes. Uma série de acontecimentos mobilizou pessoas e imprensa em torno das publicações do grupo e, a partir de um esforço coletivo de observação sobre esses acontecimentos e publicações, nosso grupo de pesquisa promoveu uma coleta de dados em sites de rede social e sites jornalísticos, de modo sistemático, nos meses de setembro e outubro de 2018. No Twitter, a coleta foi orientada pelo uso das hashtags \#MulheresContraBolsonaro, \#MulheresComBolsonaro, \#ÉPelaVidaDasMulheres e \#EleNao. No Facebook, acompanhamos páginas de veículos jornalísticos e coletamos os textos que remetiam ao grupo.

\footnotetext{
1 Já em exercício, Bolsonaro determinou ao Ministério da Defesa que no dia 31 de março de 2019 fossem realizadas comemorações em unidades militares, em alusão ao início do período que ficou conhecido como Ditadura Civil-Militar no Brasil. Reações negativas à determinação fizeram o judiciário proibir celebrações oficiais dos 55 anos do golpe de 1964. Fonte: https://www.bbc.com/portuguese/brasil-47741593. Acesso em: 04 abr. 2019.

2 Na sessão da Câmara dos Deputados que votou o Impeachment da ex-presidenta Dilma Roussef, Bolsonaro afirmou que Ustra era o "pavor" de Dilma, torturada na época da ditadura. Fonte: https://bbc.in/2XrAvtk. Acesso em: 04 abr. 2019.

${ }_{3}^{3}$ Disponível: https://bit.ly/2L2gkQX. Acesso em: 15 out. 2018.

4 Disponível em: https://www.facebook.com/GilbertoDimenstein/videos/723743951300554/. Acesso em: 15 out. 2018.
} 
Assim, o objetivo deste artigo é relatar como a formação do grupo Mulheres Unidas Contra Bolsonaro se constituiu em um ciberacontecimento (HENN, 2014), entendendo este conceito como referência a acontecimentos engendrados em redes digitais, via processos transnarrativos e cuja natureza carrega em si características da cultura digital. Nosso objeto não são as interações que tiveram lugar no grupo, mas sim as narrativas sobre a processualidade de sua constituição. Como veremos, diferentes campos, instituições e atores disputam o lugar preferencial de narrador do acontecimento. Com isso, coloca-se em discussão a luta das mulheres por espaço no debate público sobre política no contexto eleitoral brasileiro, problematizando a relação entre a apropriação que grupos como esse fazem de espaços digitais e a cobertura realizada pela imprensa sobre essa apropriação.

Para alcançar esse objetivo, organizamos este texto em dois tópicos. Primeiro, descrevemos o funcionamento da circulação de sentidos na qual emerge o grupo. Para tanto, inscrevemos o acontecimento numa linha cronológica e analisamos as operações midiáticas a partir do mapeamento realizado nas redes. No segundo tópico, detemo-nos principalmente no material coletado nos sites noticiosos e analisamos de que modo as discursividades jornalísticas construíram o acontecimento em tensão com as narrativas difusas advindas das redes sociais.

\section{A constituição do grupo como ciberacontecimento}

Com base nas transformações visivelmente significativas no entendimento dos papeis de gênero na constituição das sociedades contemporâneas (BLAY, 1999; PINTO, 2003), este estudo busca compreender as configurações de práticas midiáticas entendendo os avanços feministas que colocaram nas agendas públicas e de pesquisa a categoria de gênero como elemento central das demarcações entre as esferas públicas e privadas (OKIN, 2008; ZELIZER, 2011).

As lutas pelas transformações no conceito de cidadania e participação política são apontadas em trabalhos como o de Scott (2002), a respeito da participação das mulheres frente aos sistemas governamentais de direito universal, nos primórdios do movimento sufragista, como formas de resistência a uma cidadania que excluía as mulheres de suas formulações. Desde essa época até a presente, as dicotomias entre as dinâmicas públicas e privadas e as diferenças nos sistemas de articulação política indicam a existência e a manutenção de um conjunto de ações políticas que estabelecem para além das agendas estabelecidas. Essas ações políticas são caracterizadas por Fraser (1999, p. 156) como 
espaços “contra-públicos subalternos”, ou seja, práticas dispersas, mas que são reunidas na forma de arenas discursivas em que os membros dos grupos subordinados inventam e articulam as possibilidades de seus contradiscursos, formulando interpretações opositoras para os problemas da realidade social que são identificados. São ações como essa que orientam a constituição do grupo Mulheres Unidas Contra Bolsonaro.

O grupo em questão, conforme estabelecido em suas regras, era destinado apenas às mulheres - cis e trans ${ }^{5}$-, fossem de direita ou esquerda, e não permitia discursos de ódio ou bullying, tampouco promoções e spam ou postagens sobre outros candidatos. O conteúdo compartilhado no grupo deveria ser mantido em segredo para não expor publicamente as participantes. Como apontam Gohn (2013) e Biroli (2018), é no interior das atuações femininas contemporâneas, entre posições progressistas, conservadoras e em relação à incorporação de uma agenda liberal, que as estratégias políticas são desenvolvidas. Dessa forma, as possibilidades de atuação na vida pública e para a participação das mulheres na esfera pública são determinadas por uma série de fatores que regem as fronteiras entre as esferas privada e pública, o que "constitui papéis, [e] produz o gênero. Mas não o faz da mesma forma para todas as mulheres" (BIROLI, 2018, p. 12).

Figura 1 - Descrição do grupo

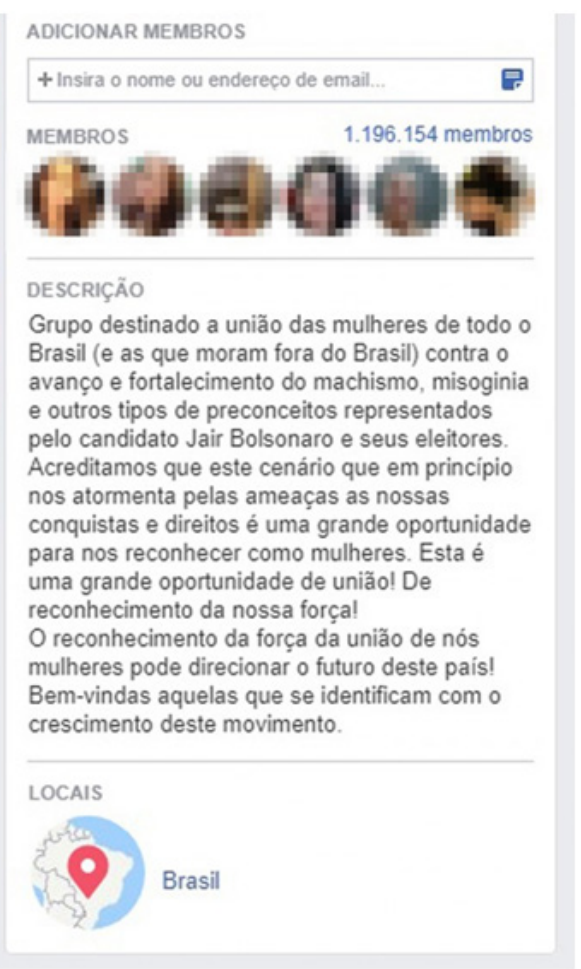

Fonte: Facebook/Reprodução. Acesso em: 10 set. 2018

${ }^{5}$ Cisgêneras são as pessoas cuja identidade e expressão de gênero concordam com o gênero designado ao nascer. Pessoas transgêneras não se identificam com as características de identidade e expressão do gênero de nascença. 
Quando o grupo começou a crescer, passou a ser comandado por nove administradoras e cerca de 50 moderadoras, que incentivavam o engajamento de eleitoras que não desejavam que Bolsonaro fosse eleito. Em pesquisa divulgada pelo instituto Datafolha na semana do dia 10 de setembro, a rejeição ao candidato entre as mulheres alcançava 49\% ${ }^{6}$. Nos primeiros dias, a entrada de apoiadoras de Bolsonaro era permitida. Quando as discussões passaram a ser marcadas por um clima hostil, o grupo tornouse fechado e destinado apenas àquelas que se declaravam contra o candidato do PSL. Seguindo as próprias configurações ofertadas pela plataforma para grupos fechados, a inclusão de novas integrantes se dava de duas formas: quem já estava dentro podia adicionar novas pessoas e quem ainda não estava poderia pedir para entrar (ambas sujeitas à avaliação da moderação).

A organização em rede das mulheres, nesse caso, gerou visibilidade pela velocidade com que novas participantes foram sendo adicionadas. Com isso, a constituição do ciberacontecimento (HENN, 2014) se dava pela própria formação do grupo que se desenvolvia devido às práticas do ambiente digital: adição de pessoas por aquelas que já estavam dentro, circulação de informação sobre o grupo através das redes, velocidade de circulação dessa informação e rápida adesão de novas participantes em pouco tempo. Ademais, os próprios conteúdos gerados no (e sobre o) grupo e espalhados em outros ambientes carregavam traços da cultura digital (áudios, gifs, memes, vídeos, entre outros). Essas características, conforme aponta Natansohn (2013), são implicação do próprio entorno tecnológico que passa a orientar as ações feministas, instaurando políticas de inclusão das mulheres no meio digital, bem como gerindo os processos conflitivos em torno da própria tecnologia.

Ainda que fechado, houve uma tentativa de abertura, com vistas à democratização do debate, na medida em que as moderadoras inicialmente permitiram a entrada de apoiadoras de Bolsonaro. O que estava acontecendo condizia com as mobilizações em rede caracterizadas por uma comunicação menos hierárquica, propiciada pela interação nas mídias digitais, entre uma multiplicidade de atores interconectados que compartilham anseios, indignações, objetivos e esperanças em comum (CASTELLS, 2013, MALINI; ANTOUN, 2013, SCHERER-WARREN, 2014). Para além disso, a formação do grupo assemelhasse às mobilizações organizadas pelos tensionamentos da inscrição feminina e da atuação política das mulheres em rede, como já discutidas por Haje (2003), Gohn (2013) e Natansohn (2013), destacando-se como constituinte das preocupações do grupo o discurso misógino, racista e homofóbico do candidato.

${ }^{6}$ Disponível em: https://glo.bo/2NEV58x. Acesso em: 15 out. 2018. 
É ainda pertinente apontar que, no sentido acontecimental, a emergência do grupo pode ser inscrita em relação a outros acontecimentos correlatos que, de certa forma, permitem sua insurgência - falamos especificamente de mobilizações feministas que emergiram em decorrência de articulações digitais, como Eu Não Mereço Ser Estuprada, Marcha das Vadias, \#meuamigosecreto, \#meuprimeiroassédio, Ni Una Menos, \#MeToo, entre outras.

Uma semana após a criação do grupo Mulheres Unidas Contra Bolsonaro, em 6 de setembro, o candidato foi esfaqueado em um ato de campanha em Juiz de Fora (MG). Nos dias seguintes, com Bolsonaro hospitalizado e as notícias sobre ele se restringindo a boletins médicos e análises sobre os rumos da campanha a partir do episódio, o grupo de mulheres cresceu exponencialmente. Com esse crescimento, a mobilização passa a ser notícia nos veículos jornalísticos na semana do dia 10 de setembro. No dia 12, o grupo chegou a um milhão de "membras" - como elas se denominavam, no feminino. Uma das criadoras do grupo fez uma publicação em comemoração, assinalando a ideia de uma solidariedade e resistência feminista forjada no/pelo coletivo:

Então somos 1 MILHÃO, um milhão de vozes que gritam e exigem serem ouvidas, somos um milhão de olhos que miram um futuro que nos contemple, um milhão de braços erguidos pela luta, um milhão de corpos que existem e resistem, de corpos que não aceitam serem violados, deixados de lado. Somos um milhão de MULHERES que não performam o papel de coadjuvantes! SOMOS PROTAGONISTAS, SENHORAS DE NOSSOS DESTINOS! (LT, integrante do grupo). ${ }^{7}$

Quando o grupo passou a ser notícia na imprensa e se tornou um dos assuntos mais comentados nas redes sociais, apoiadores de Bolsonaro criaram outros espaços no Facebook em favor ao candidato. Assim, a visibilidade que o grupo atinge ao agregar um grande número de participantes mobiliza não só atores que se articulam para combater esse crescimento, mas também a imprensa, que começa a gerar conteúdo sobre como a mobilização feminina se organiza para impedir a vitória de Bolsonaro. Há, nesse sentido, um acontecimento singular e de ruptura, pois não se trata de um grupo de apoio ou de um movimento em prol de um candidato, como é comum em outros processos eleitorais. Nesse caso o levante foi para impedir a continuidade ou a vitória de uma determinada candidatura. $\mathrm{O}$ ciberacontecimento acontece no momento em que o comum surge pela necessidade de combate ao incomum, no caso de outros grupos que surgiram a favor de

\footnotetext{
${ }^{7}$ Disponível em: https://bit.ly/2XVSzQF. Acesso em: 15 out. 2018.
} 
Bolsonaro, na tentativa de desviar a atenção do grupo das mulheres, e quando a imprensa volta sua atenção para este grupo, na tentativa de desvendar alguns boatos e noticiar a organização das mulheres em torno de um objetivo - ainda que nem todas tivessem um voto em comum.

Destacam-se dois grupos que atuaram na forma de combater o grupo das mulheres. O primeiro, nomeado de Mulheres Unidas A FAVOR de Bolsonaro ${ }^{8}$, reunia aproximadamente 73 mil participantes até metade de outubro. Para participar do grupo, era necessário, antes, curtir a página "Bolsonaro Heroi Nacional”. À época, o grupo foi criticado por ser um grupo de mulheres cuja moderação era exercida majoritariamente por homens. Na verdade, este grupo havia sido criado em fevereiro de 2017, tendo então sofrido alterações de nome. Em outubro de 2018 foi denominado de Presidente Bolsonaro 17.

Outro grupo a favor do candidato é o Mulheres Com Bolsonaro \#17 (OFICIAL)9. Esse grupo tornou-se o principal grupo de oposição ao das mulheres que se uniram contra o candidato, com mais de 400 mil membros. A época de sua criação, a moderação também era, em sua maioria, feita por homens. A criação e nomeação desses grupos indica como operação enunciativa a construção de uma narrativa que buscava mostrar que havia muitas mulheres favoráveis ao candidato. Esse será uma operação importante na disputa de narrativas sobre a constituição do grupo e no processo de deslegitimação que passa a ocorrer a partir de então.

É interessante notar que outras páginas, mais antigas, foram importantes articuladoras para a divulgação desses grupos. Um exemplo é a página Apoiamos a Operação Lava Jato- Juiz Sérgio Moro ${ }^{10}$, criada em 10 de março de 2016, que conta com 1.081.928 curtidas e compartilhou 17 postagens da página Mulheres unidas A FAVOR de Bolsonaro entre os dias 10 e 12 de setembro no Facebook. Ou seja, ainda que as páginas e grupos a favor de Bolsonaro não alcançassem tantos membros como o grupo contra o candidato, eles contavam com uma ativa circulação em vários grupos pró-Bolsonaro inclusive em páginas com conteúdos turbinados a favor do candidato ${ }^{11}$.

Nas imagens abaixo (Figura 2), alguns exemplos de publicações no Twitter em resposta à mobilização Mulheres Unidas Contra Bolsonaro. Nesse momento, passa a

8 O grupo mudou de nome para "Homens e mulheres unidos A FAVOR de Bolsonaro". Disponível em: https://www.facebook.com/groups/504051349719019/?_fns\&hash=Ac3SsuFL0Le1 is6-. Acesso em: 16 out. 2018.

${ }^{9}$ Fonte: https://www.facebook.com/groups/324942994731554/?ref=br_rs. Acesso em: 4 abr. 2019.

${ }^{10}$ Fonte: https://www.facebook.com/apoiosergios2moro/ Acesso em: 4 abr. 2019.

11 Em agosto, o TSE já havia apresentado uma ordem judicial ao Facebook para retirar do ar conteúdos turbinados a favor de Bolsonaro que foram veiculados pela página do empresário Luciano Hang. 
ser utilizada a hashtag \#MulheresComBolsonaro. A imagem do meio, curiosamente, se apropria de uma famosa ilustração feminista, inserindo nela signos que remetem ao candidato. Na imagem à direita, um dos filhos de Bolsonaro, o então candidato ao Senado Flávio Bolsonaro, publica um vídeo no qual mulheres cantam uma música em favor do candidato. Nas três publicações, está presente a remissão à bandeira brasileira.

Figura 2 - Tweets a favor de Bolsonaro.
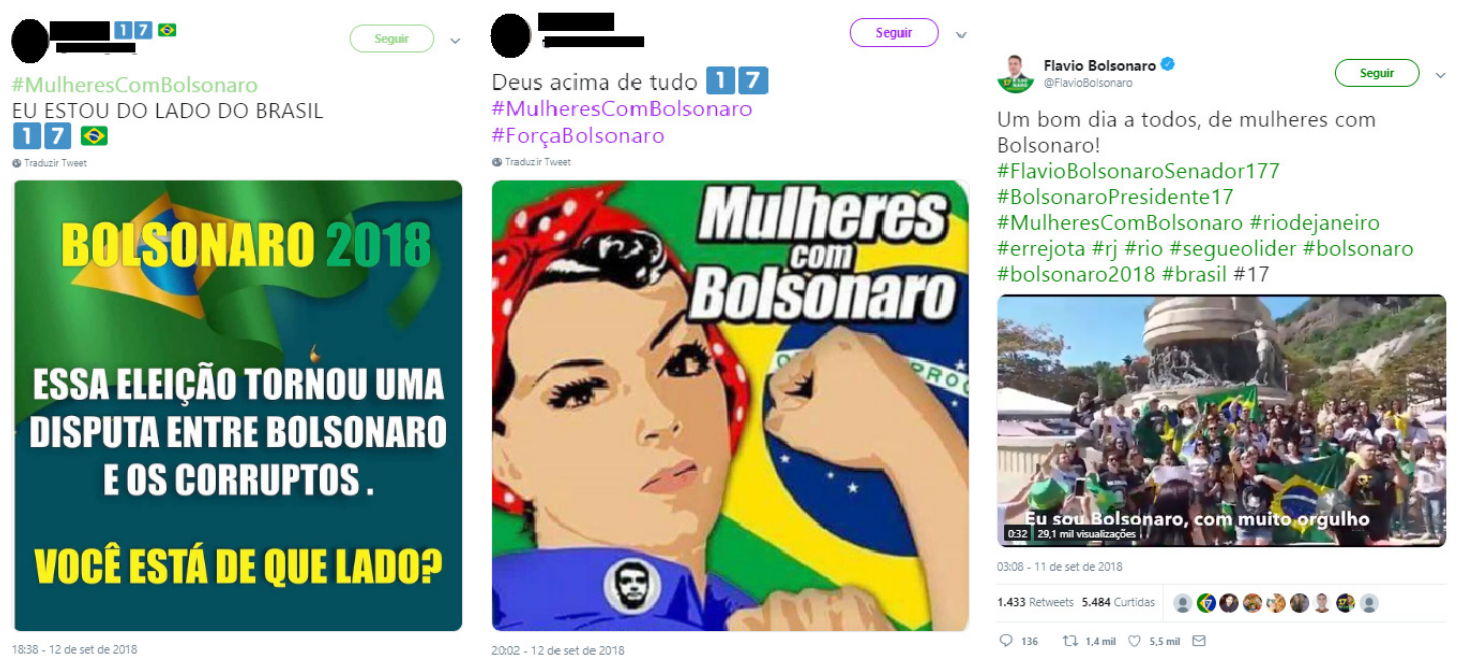

Fonte: Twitter/Reprodução

A partir da ascensão da comunidade, noticiada pela imprensa e alçada ao topo dos Trending Topics do Twitter, com a hashtag \#MulheresContraBolsonaro, o grupo passou a ser alvo de boatos que tentavam desmentir o alto número de participantes e a sua criação. Um dos boatos afirmava que o grupo Mulheres Unidas Contra Bolsonaro era, na verdade, um grupo de Facebook voltado ao humor (Gina Indelicada), criado já há alguns anos e que contava com milhares de integrantes. Segundo o boato, o grupo havia sido vendido e seu nome alterado - o que justificaria o grande número de participantes (Figura 3). O boato teve alto grau de espalhabilidade nas redes e sua propagação se deve também ao seu compartilhamento por perfis públicos e com grande número de seguidores, como do então candidato à deputado federal Eduardo Bolsonaro (Figura 4). 
Figura 3 - Tweets sobre o boato da venda do grupo.

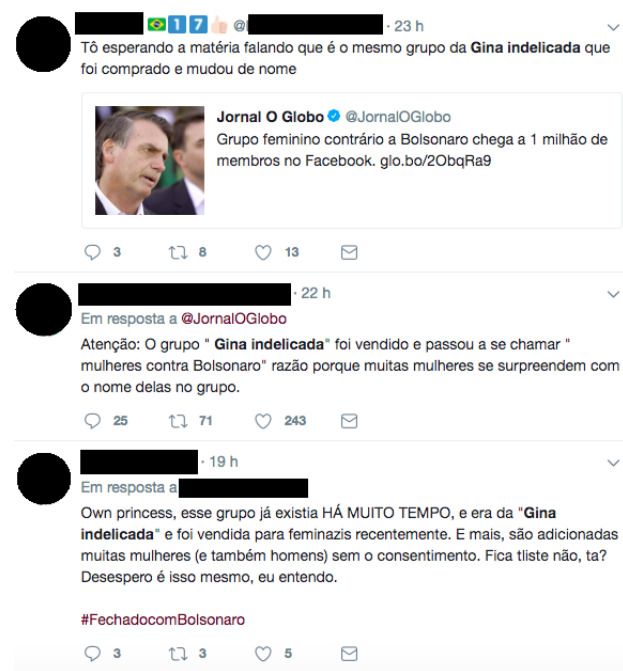

Fonte: Twitter/Reprodução

Figura 4 - Publicação de Eduardo Bolsonaro

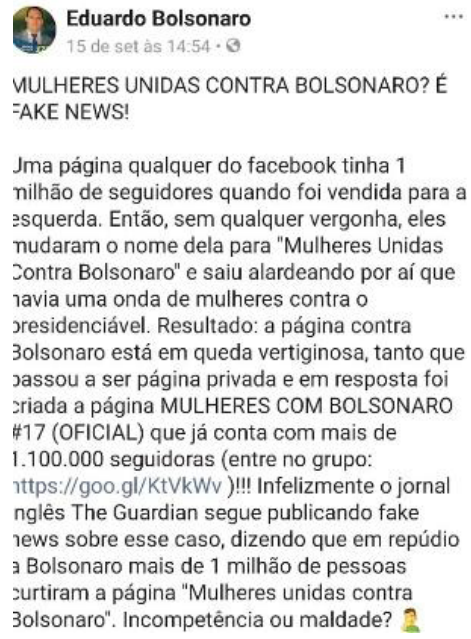

Fonte: Facebook/Reprodução

O boato foi desmentido pelo próprio criador do grupo Gina Indelicada (que ainda existe, não foi vendido). O Facebook também se pronunciou, afirmando que, quando um grupo tem o nome alterado, todos os seus integrantes são avisados via notificação. De qualquer modo, era impossível o grupo ter sido comprado, visto que a data de sua criação não poderia ser alterada e fica visível para todos: 30 de agosto de 2018 .

Outro boato que buscava deslegitimar o grupo era de que havia muitas mulheres que estavam lá, mas que não haviam pedido para entrar. Além disso, quando as integrantes 
comemoraram a marca de um milhão de membras, qualquer pessoa que não estivesse no grupo e visitasse a página veria que o número era menor. O porta-voz do Facebook explicou que, enquanto as pessoas de fora do grupo visualizam apenas o número de integrantes aprovados, os próprios participantes do grupo conseguem ver o número total de pessoas - tanto as aprovadas quanto as que pediram para entrar, mas que ainda não tiveram o convite aceito pela moderação $0^{12}$.

Observamos até aqui algumas operações importantes para compreender a constituição do ciberacontecimento. Sua emergência se dá nas redes digitais, não apenas com a criação do grupo no Facebook, mas também com as narrativas que passam a circular com vistas a formar o coletivo - a partir da circulação de conteúdos em diferentes formas (memes, gifs, áudios, imagens e relatos pessoais sobre o coletivo), organizados em torno de hashtags. Quando o coletivo cresce, narrativas contrárias surgem e se espalham nas redes, também em diferentes formatos e indexadas por hashtags, com o objetivo de deslegitimar o grupo. O falseamento de informações e a criação de boatos operam na sustentação dessas narrativas. Atores de diferentes campos enunciam inteligibilidades acerca das questões envolvendo o grupo. Um desses campos é o jornalístico. Na sequência, descrevemos algumas dessas discursividades que demonstram a complexidade do trabalho de enunciação do ciberacontecimento.

\section{A cobertura na imprensa}

No período em que a legitimidade sobre a criação do grupo era motivo de disputa, uma série de veículos jornalísticos se preocupou em apresentar checagens para demonstrar que o grupo não era falso, o que revelou mais cuidado na elaboração das chamadas das matérias nos sites. No UOL, a notícia Grupo contra Bolsonaro não mudou nome para atrair mais mulheres ${ }^{13}$ teve mais de 10 mil interações na rede ${ }^{14}$, mas observando sua trajetória se vê que esteve majoritariamente vinculada ao compartilhamento em páginas de sites e blogs do campo da esquerda. Já o El País noticiou Campanha de Bolsonaro mente sobre mobilização de mulheres contra o candidato no Facebook ${ }^{15}$ também procurando explicitar que a iniciativa era real e passou a ser desacreditada por ataques promovidos por pessoas da campanha de Bolsonaro. A publicação tem mais de 95 mil interações nas

${ }_{12}$ Disponível em: https://bit.ly/32obgf5. Acesso em: 15 out. 2018.

${ }_{13}$ Fonte: https://bit.ly/2DaobZE. Acesso em: 5 abr. 2019.

${ }^{14}$ A medição das interações apresentadas neste artigo foi realizada com o auxílio da ferramenta CrowdTangle. O resultado das métricas foi obtido em 15 out. 2018.

${ }^{15}$ Fonte: https://bit.ly/2Ox5zUJ. Acesso em: 5 abr. 2019. 
redes, mas, outra vez, se dão a partir de páginas ou pessoas que se distanciam do campo político de Bolsonaro. Os compartilhamentos das páginas Quebrando o Tabu, Mídia Ninja e da jornalista Mônica Iozzi estão entre os que mais repercutiram.

Na sequência, foi notícia na imprensa a agressão a uma das administradoras do grupo. No Estadão, a publicação recebeu o título Organizadora de grupo contra Bolsonaro relata agressão no Rio ${ }^{16}$. A reportagem, contextualizada com outros casos que se destacavam nas redes sociais, como o da cantora Marília Mendonça, ameaçada depois de se posicionar contra a candidatura de Bolsonaro, teve mais de 79 mil interações nas redes sociais. Outra vez, é possível notar que a repercussão é maior dentro de páginas como a do próprio grupo atacado ou da candidata Sâmia Bonfim (PSOL).

Em uma espécie de resposta ao grupo contrário a Bolsonaro, também surgiram articulações online de apoio ao candidato do PSL. Uma jornalista do UOL entrou em um desses grupos e colheu relatos de mulheres para uma reportagem. Ela, no entanto, acabou expulsa dois minutos depois e, após a publicação da matéria ${ }^{17}$, teve sua conta no WhatsApp invadida ${ }^{18} \mathrm{e}$ todas as conversas, fotos, vídeos e contatos apagados. Somadas, as duas notícias - sobre as participantes do grupo e a respeito da invasão do celular da repórter -, não chegam a alcançar 20 mil interações nas redes sociais, a maioria dentro da própria página do UOL no Facebook. Já uma notícia publicada no site da revista Exame ${ }^{19}$ sobre um dos grupos de mulheres que apoiam o candidato do PSL alcançou mais de 119 mil interações. Fora da Exame, a página em que a notícia mais repercutiu se chama Bolsonaro da Depressão - de apoio ao candidato. Nela, a postagem que traz o link e incentiva as mulheres a ajudarem o grupo a crescer tem mais de 1.700 compartilhamentos.

$\overline{16}$ Fonte: https://bit.ly/2Q5Yv1K. Acesso em: 5 abr. 2019.

${ }_{17}$ Fonte: https://bit.ly/2NmOGzr. Acesso em: 5 abr. 2019.

${ }^{18}$ Fonte: https://bit.ly/2XHep68. Acesso em: 5 abr. 2019.

19 Fonte: https://bit.ly/2Y9cfAF. Acesso em: 5 abr. 2019. 
Figura 5 - Postagem no grupo Bolsonaro da Depressão
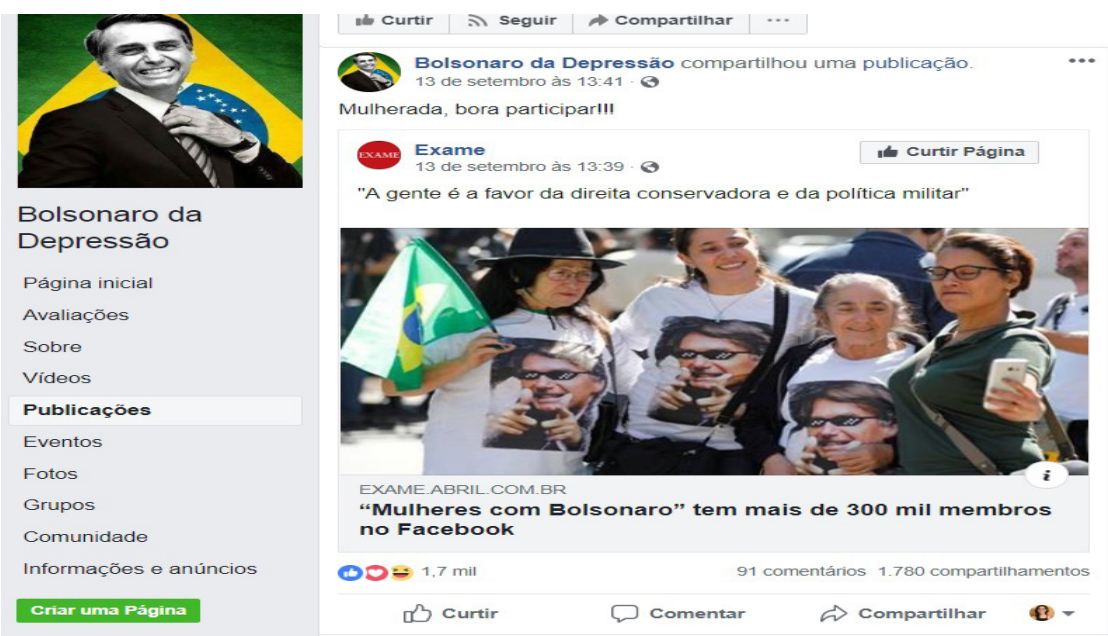

Fonte: Facebook/Reprodução

No dia 15 de setembro, após sucessivos ataques, o grupo foi hackeado. Os ataques tiveram início quando uma das administradoras teve o perfil invadido e seus dados expostos, dois dias antes. As outras administradoras foram chantageadas, via WhatsApp, com a exigência de remoção da página, como condição para seus dados pessoais não serem divulgados. A foto de capa foi alterada, o nome do grupo modificado para Mulheres COM Bolsonaro e publicações ofensivas foram postadas ${ }^{20}$. As administradoras das páginas criaram um abaixo-assinado pedindo que o Facebook devolvesse o grupo a elas - o que ocorreu no mesmo dia. $\mathrm{O}$ crime foi denunciado à Polícia Federal como crime cibernético.

Naquele domingo, no Twitter, a hashtag \#MulheresContraOBolsonaro chegou a ocupar o segundo lugar nos Trending Topics do Twitter, reunindo mensagens em apoio à ação feminina e contra a remoção da página ${ }^{21}$. O episódio motivou a criação de outras duas mobilizações: \#EleNunca, ainda no domingo, e \#MeuBolsominionSecreto, que passou a ser utilizada no dia 17 de setembro e que ironizava as incoerências dos apoiadores do candidato do PSL.

Destaca-se abaixo um trecho de um texto publicado no Facebook e compartilhado 850 vezes, no qual uma das integrantes do grupo analisa a sua constituição. Ancorada em alguns relatos feitos no grupo, a autora identifica que as análises até então realizadas não conseguiram pensar na potência articuladora do feminino que constituiu a mobilização muito provavelmente porque a maioria dos analistas políticos são homens e nem acesso

\footnotetext{
20 Nota oficial disponível em: https://www.facebook.com/mulherescontraofascismo/posts/196947961076427. Acesso em: 15 out. 2018.

${ }^{21}$ Disponível em: https://bit.ly/2SbvwMd. Acesso em: 15 out. 2018.
} 
ao grupo tinham e, principalmente, porque suas análises tergiversam a perspectiva de gênero necessária para a compreensão de uma prática política diversa da convencional (masculinista), mas sim orientada pela alteridade, subjetividade e solidariedade. Propõese, portanto, um outro modo de fazer política, um modo feminino.

[...] Ao partir de variáveis como 'esquerda' vs. 'direita', 'militantes de partidos' vs. 'despolitizados', 'elite' vs. 'povo', 'antipetismo vs. petismo', os analistas tradicionais de eleições não conseguem entender como o feminino atravessa essas distinções e as dilui, torna mais complexas ou reinventa. A política entre as mulheres tem um tom pessoal e íntimo; de desabafo, de apoio mútuo. Nas redes e fora delas. O Bolsonaro para as mulheres não é, assim, só um candidato. É uma força concreta, que afeta as suas relações na sociedade, as suas relações pessoais e familiares, especialmente com os homens, sua liberdade e existência. Quando uma moça posta no grupo sobre os ataques virtuais ou físicos de eleitores do Bolsonaro, não se trata um "argumento contra o candidato". Se trata de uma compreensão muito mais profunda, prática, do perigo que está diante de nós. É esse tom que permite que eleitoras do Boulos, Amoêdo, Marina e cabo Daciolo se entendam. Que mulheres do Sul, Nordeste, interior e grandes cidades se reconheçam (CM, integrante do grupo, 2018) $)^{22}$.

Antes de o grupo ser hackeado, já havia uma movimentação que incentivava manifestações de rua contra Bolsonaro. Depois que o grupo foi recuperado, a ideia de uma manifestação pública tomou mais força e se proliferaram eventos na rede social que convidavam para os atos em diferentes cidades do país. $\mathrm{O}$ ato, que foi batizado como \#EleNão (em alguns lugares, também Mulheres Contra Bol.so.na.ro), ocorreu em 65 cidades, no dia 29 de setembro, levando centenas de milhares de pessoas às ruas. A BBC Brasil"23 chamou de "manifestação histórica" a mobilização contra o candidato. A reportagem com cerca de 88 mil interações nas redes aborda também as mobilizações ocorridas fora do país, além de ouvir analistas e discutir a importância da articulação online para o feito. A postagem, assim como outras, repercute especialmente em páginas que são críticas ao candidato, como Mídia Ninja, Todas Fridas e Deboas na Revolução.

Em outros veículos de imprensa, como o Estadão, encontramos reportagens que procuram demonstrar algum equilíbrio entre as manifestações contra e a favor de Bolsonaro. Com o título Rio de Janeiro tem manifestações a favor e contra Bolsonaro,

22 Disponível em: https://drive.google.com/open?id=1 cbqyexgre-4DFFgpMCplRfpozfC3nKo1. Acesso em: 15 out. 2018.

${ }^{23}$ Fonte: https://www.bbc.com/portuguese/brasil-45700013 Acesso: 15 out. 2018 
a notícia ${ }^{24}$ não fala no número de pessoas nas ruas. Além de dar praticamente o mesmo espaço às duas mobilizações, destaca que, na contrária ao candidato, tinha muitas bandeiras partidárias. Já na favorável, cita uma das líderes, que dizia ser um movimento de "paz e amor", além de uma mãe negra e um homem gay. Com abordagem semelhante, O Globo ${ }^{25}$ também reuniu os atos a favor e contra Bolsonaro numa mesma reportagem. A matéria cita, por exemplo, que na manifestação contra o candidato eram vendidas camisetas com a estampa "Lula Livre". A legenda de uma das fotos também afirma que "centenas de pessoas se reuniram na Cinelândia”.

Um dos maiores atos foi o realizado no Largo da Batata, em São Paulo, onde a organização estimou o número de participantes em 150 mil. O site da Revista Veja ${ }^{26}$, por exemplo, chegou a publicar que centenas de pessoas se juntaram ao ato, mas alterou o título para milhares, como é possível confirmar comparando link e título da matéria. A manifestação acabou atacada por um novo modelo de fake news: a falsa checagem. Uma reportagem do Estadão sobre o pré-Carnaval de Pinheiros, de fevereiro de 2017, que falava sobre o grande número de foliões no local, passou a ser compartilhada em páginas de apoiadores de Bolsonaro afirmando que as notícias sobre o ato do dia 29 traziam imagens manipuladas, do Carnaval do ano anterior. Na sequência, uma série de veículos publicaram checagens negando a manipulação e confirmando que a multidão protestava mesmo contra Bolsonaro. O Estadão ${ }^{27}$ publicou: Disseminadores de boatos promovem falsa checagem sobre protesto contra Bolsonaro. O Correio Braziliense ${ }^{28}$ também tratou de desmentir o boato: Criadores de boatos promovem falsa checagem sobre protesto contra Bolsonaro. O mesmo ocorreu no $\mathrm{G}^{29}$ : É \#FAKE que imagem de ato contra Bolsonaro no Largo da Batata é do carnaval de 2017.

Chama atenção o fato de que as notícias do G1 e do Correio Braziliense têm poucas interações - menos de 300, somadas -, somente em páginas críticas a Bolsonaro. Já a publicação do Estadão, com mais de 67 mil interações, acabou por ser compartilhada em uma página de apoio ao candidato do PSL. A postagem incita os leitores a cancelarem assinatura do jornal, diz que todas as suas notícias são fake e que uma mobilização na Paulista em apoio ao candidato teria reunido mais de 1 milhão de pessoas. Nos 137 comentários da postagem, só uma pessoa questiona o que está sendo dito e tenta

${ }^{24}$ Fonte: https://bit.ly/2YWkNbe. Acesso: 15 out. 2018

${ }^{25}$ Fonte: https://glo.bo/2xNM7wJ. Acesso: 15 out. 2018.

${ }^{26}$ Fonte: https://bit.ly/2XGVSfc. Acesso: 15 out. 2018.

${ }^{27}$ Fonte: https://bit.ly/2Oi91G3. Acesso: 15 out. 2018.

${ }^{28}$ Fonte: https://bit.ly/2Jx0zPQ. Acesso: 15 out. 2018.

${ }^{29}$ Fonte: https://glo.bo/2OX0gBk. Acesso: 15 out. 2018. 
argumentar com os demais. Todos os outros reforçam as críticas à imprensa e endossam o apoio a Bolsonaro e a crença que a imagem teria sido manipulada. Alguns até afirmam ler a checagem, mas sem indicar qualquer efeito sobre seus posicionamentos. Uma mulher, por exemplo, afirma: "Leio tudo vejo tudo, mas não mudo d[e] ideia, 17 dia 7".

Falsas checagens também viralizaram a respeito da mobilização no Rio. Uma versão falsa sobre uma das fotos do ato na Cinelândia se espalhou pelas redes sociais afirmando que a imagem era antiga. A checagem publicada em $\mathrm{O}$ Globo ${ }^{30}$, que confirma a autenticidade da imagem, teve pouco mais de 4,7 mil interações, na própria página ou em outras que criticam Bolsonaro.

A Agência Lupa ${ }^{31}$, da revista piauí, também publicou uma checagem sobre um vídeo que circulava no Facebook com mais de 56 mil compartilhamentos - apenas naquele dia - mostrando um protesto contra a então presidenta Dilma Rousseff, realizado em dezembro de 2016, na Praia de Copacabana, como se fosse do dia 29, de apoio a Jair Bolsonaro. A verificação circulou principalmente em páginas contrárias ao candidato do PSL, como Brasil Contra Jair Bolsonaro, Ruth Sheherazade e Questione.

Cabe destacar que, desde que o grupo no Facebook ganhou notoriedade, a imprensa vinha noticiando a rejeição de Bolsonaro entre as mulheres. Matéria do UOL ${ }^{32}$ do dia 27 de setembro, por exemplo, se ampara na pesquisa Ibope do dia anterior, indicando que, enquanto a rejeição ao candidato entre os homens é de $44 \%$, entre as mulheres atinge 52\%. $\mathrm{Na}$ reportagem, assim como fazem os seguidores do candidato em muitas postagens, o presidente do PSL rechaça a credibilidade do levantamento e diz que as mulheres estão com Bolsonaro.

Após as mobilizações do \#EleNão, no entanto, emergem análises que questionam o efeito dos protestos nas ruas, liderados por mulheres, em um possível aumento da rejeição ao candidato. No dia 1 de outubro, a BBC Brasil ${ }^{33}$ apresenta um estudo feito por pesquisadores do Grupo de Pesquisa em Políticas Públicas para o Acesso à Informação da Universidade de São Paulo (USP) indicando que, no caso da capital paulista, ao menos, o público que foi ao Largo da Batata tinha um perfil bastante homogêneo e que seria uma "forte expressão de rejeição de quem já rejeitava o candidato". O levantamento chama a atenção para indicativos como a alta taxa de identificação com partidos como PSOL (34\%) e PT (30\%) entre os participantes do ato. Na reportagem, o pesquisador Pablo Ortellado menciona que um indicativo de sucesso seria se a mobilização tivesse

30 Fonte: https://glo.bo/2xNhIyc. Acesso: 15 out. 2018.

31 Fonte: https://bit.ly/30vFTgF. Acesso: 15 out. 2018

32 Fonte: https://bit.ly/2O27CEi. Acesso: 15 out. 2018

33 Fonte: https://www.bbc.com/portuguese/brasil-45702409 Acesso: 15 out. 2018 
levado às ruas mais pessoas identificadas com siglas como PSDB, MBD e Novo, que estariam migrando o voto para Bolsonaro. Fora da BBC, onde a notícia mais repercutiu foi na página Conservadores, sob a frase "a geração dos mimados que não trabalham". A postagem, com mais de 1.600 compartilhamentos, reúne especialmente ataques a quem participou das mobilizações, como "vagabundo ou socialista de iPhone", à própria BBC e à USP.

Figura 6 - Postagem foi usada para ataques a quem esteve no ato

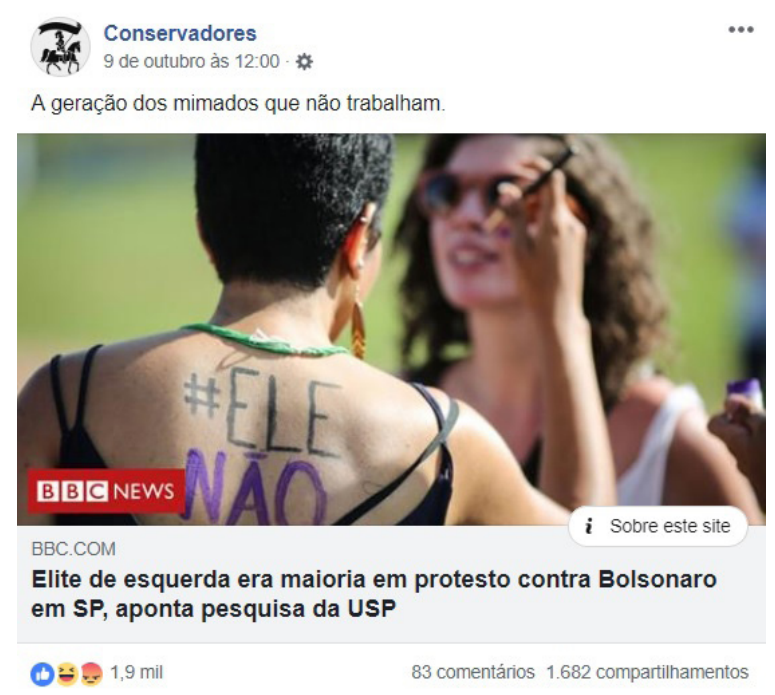

Fonte: Facebook/Reprodução

Entre editoriais e artigos de opinião, é possível identificar especialmente dois movimentos entre os principais jornais do país na reta final do primeiro turno da campanha: o primeiro, de buscar uma posição mais ao centro, embora não explícita, de alinhamento a partidos como o PSDB. É o caso do editorial do Estadão, publicado em 25 de setembro sob o título "A insensatez das elites" ${ }^{34}$, que coloca em extremos opostos as candidaturas de Bolsonaro e Fernando Haddad (PT), a partir de uma carta aberta escrita pelo ex-presidente Fernando Henrique Cardoso (PSDB). O compromisso com a democracia aparece como pano de fundo à tomada de posição do jornal.

Conforme o segundo turno se desenhava entre os candidatos do PT e do PSL, que cresce nas pesquisas na reta final, após a mobilização \#EleNão, avança na imprensa a bandeira da democracia, com críticas mais ou menos diretas a Bolsonaro. A Revista Época publica o editorial "Basta de ditaduras! Fora, golpistas" ${ }^{35} \mathrm{em}$ que relembra o apoio do jornal O Globo, do mesmo grupo ao qual pertence, ao golpe militar de 1964 e destaca a importância de repudiar qualquer risco de ruptura à normalidade democrática.

${ }^{34}$ Disponível em: https://bit.ly/2GbrYEN. Acesso em: 15 out. 2018

${ }^{35}$ Fonte: https://epoca.globo.com/basta-de-ditaduras-fora-golpistas-23098342. Acesso em: 15 out. 2018. 
A partir da observação fica evidente uma postura da imprensa orientada por pretensas imparcialidade e objetividade na cobertura. Conforme vamos nos aprofundando em um número maior de notícias, no entanto, percebemos uma narrativa que polariza candidatos não necessariamente opostos e que serve ao discurso construído nas redes sociais, especialmente pela candidatura de Jair Bolsonaro. Não à toa, as reportagens são usadas por apoiadores dos diferentes espectros políticos apenas para reforçar conceitos e ideologias, sem nenhum interesse perceptível em provocar reflexão, discussão ou compreensão real dos acontecimentos.

\section{Considerações finais}

A formação do grupo Mulheres Unidas contra Bolsonaro gerou uma repercussão de longo alcance nas redes digitais, que foi imediatamente vista pela imprensa como objeto de pauta. A rapidez com que novas integrantes eram aceitas no grupo gerou matérias sobre como a força de organização feminina poderia, talvez, impedir a vitória do candidato nas urnas. A atividade nas redes também era ágil, e assim os apoiadores de Bolsonaro se mobilizaram para tentar derrubar o grupo. Em determinado momento os veículos jornalísticos passaram a priorizar pautas relacionadas a fatos que colocavam em dúvida a legitimidade do grupo das mulheres: se havia sido criado mesmo para tal fim ou se havia sido apenas um outro grupo já existente, cujo nome tivesse sido alterado. Os boatos se sobrepuseram ao objetivo inicial do grupo; os ataques cibernéticos que tentaram se apropriar do espaço de luta criado pelas mulheres também foram motivo de pauta jornalística e nas redes digitais as forças de um ambiente polarizado se enfrentaram através de posts, mensagens e também pelo compartilhamento desses conteúdos jornalísticos para tentar alavancar os posicionamentos que condiziam com suas ideologias políticas no momento.

O texto, assim, mostra uma articulação em rede que pauta o jornalismo, mas que pelas forças de um embate polarizado, muitas vezes invisibiliza questões de importância política e social. As mobilizações de rua impulsionadas pelo grupo criado pelas mulheres revelam a potencialidade da luta feminista pelo espaço no debate público sobre política. $\mathrm{O}$ ciberacontecimento se constitui pelo envolvimento de esferas de produção e consumo de conteúdos por diversos atores. A produção de sentidos acerca do acontecimento parte da formação do grupo, mas se desdobra nos outros fatos que envolvem as administradoras, os outros grupos criados posteriormente, os veículos jornalísticos entre todas as outras 
pessoas e mídias que formam essa rede de desdobramentos. É evidente que por vezes o mote central do próprio grupo se perca, diante da pluralidade de sentidos que se produz nesse contexto; ao mesmo tempo em que é necessário prestar a atenção em como as pautas e as finalidades das mobilizações podem e por vezes são apropriadas de modo perverso.

\section{Referências}

BIROLI, F. Gênero e desigualdades: limites da democracia no Brasil. São Paulo: Boitempo, 2018.

BLAY, E. A. Gênero e políticas públicas ou sociedade civil, gênero e relações de poder. In: SILVA, A. L.; LAGO, M. C. S.; RAMOS, T. R. O. (Org.). Falas de gênero: teorias, análises, leituras. Florianópolis: Editora Mulheres, 1999, p. 133-147.

CASTELLS, M. Redes de Indignação e esperança: Movimentos sociais na era da internet. Rio de Janeiro: Zahar, 2013.

FRASER, N. Repensando la esfera pulica: uma contribución a la crítica de la democracia actualmente existente. Equador Debate, n. 46, p. 139-173, abr. 1999.

GOHN, M. G. Movimentos sociais e redes de mobilizações civis no Brasil contemporâneo. Petrópolis: Vozes, 2013.

HAJE, L. Esferas públicas feministas na Internet. LOGOS, v. 10, n. 2, p. 88-105, 2003.

HENN, R. El ciberacontecimiento: producción y semiosis. Barcelona: Editorial UOC, 2014.

MALINI, F.; ANTOUN, H. A internet e a rua: ciberativismo e mobilização nas redes sociais. Porto Alegre: Sulina, 2013.

NATANSOHN, G. Qué tem a ver as tecnologías digitais como o género? In: NATANSOHN, G. (Org.). Internet em código feminino. Teorias e práticas. Buenos Aires: La Crujía, 2013, p. 15-38.

OKIN, S. M. Gênero, o público e o privado. Estudos Feministas, n. 16, v. 2, p. 305-332, 2008. 
PINTO, C. R. J. Uma história do feminismo no Brasil. São Paulo: Ed. Fundação Perseu Abramo, 2003.

SCOTT, J. W. A cidadã paradoxal: as feministas francesas e os direitos do homem. Florianópolis: Editora Mulheres, 2002.

SCHERER-WARREN, I. Redes de movimentos sociais. São Paulo: Edições Loyola, 2014.

ZELIZER, V. A negociação da intimidade. Petrópolis: Vozes, 2011.

1 Docente e pesquisadora no Programa de Pós-Graduação em Ciências da Comunicação da Universidade do Vale do Rio dos Sinos. Doutora e mestra em Comunicação e Informação pela Universidade Federal do Rio Grande do Sul. Pós-doutora em Ciências da Comunicação. Pesquisadora no LIC - Laboratório de Investigação do Ciberacontecimento.E-mail: aquino.mariaclara@gmail.com.

2 Doutorando no Programa de Pós-Graduação em Ciências da Comunicação da Unisinos (São Leopoldo, RS, Brasil). Integrante do LIC - Laboratório de Investigação do Ciberacontecimento. E-mail: marlon.smdias@gmail.com.

3 Mestranda no Programa de Pós-Graduação em Ciências da Comunicação da Unisinos (São Leopoldo, RS, Brasil). Integrante do LIC - Laboratório de Investigação do Ciberacontecimento. E-mail: anakaavila@gmail.com. 